\title{
Tensile Behaviour and Durability Issues of Engineered Cementitious Composites with Rice Husk Ash
}

Débora Pedroso Righi ${ }^{1}$, Fernanda Bianchi P. da Costa ${ }^{1}$, Ângela Gaio Graeff ${ }^{1}$, Luiz Carlos Pinto da Silva Filho ${ }^{1}$

\author{
${ }^{1}$ Laboratório de Ensaios e Modelos Estruturais - LEME - UFRGS, Porto Alegre, RS \\ e-mail: righi.p.debora@gmail.com; fernanda.bcp@gmail.com; angel.graeff@gmail.com; lcarlos66@gmail.com
}

\begin{abstract}
The Engineered Cementitious Composites (ECC) is a special type of High Performance Fibre Reinforced Cementitious Composite (HPFRCC) characterized by a high tensile ductility with a $\%$ maximum volume of micro fibres. ECC has a tensile strain-hardening performance that leads to multiple cracking behaviour, thus providing the high ductility to the concrete. One of the main applications of ECC is as structural reinforcement in the construction or rehabilitation of rigid and flexible pavements. In order to adapt the ECC to the Brazilian environment, polypropylene fibres have been used instead to PVA fibres. Moreover, rice husk ash (RHA) has also been used as a partial replacement to cement, aiming to produce an environmentally friendly and a more economically viable version of the ECC. This work presents the results obtained for ECC mixtures containing 10\%,20\% and 30\% (by volume) of non-processed rice husk ash, as a replacement to cement. An experimental study has been carried out to investigate the tensile behavior and durability issues of these ECCs. The results indicate that the use of RHA is technically viable and that the replacement of $30 \%$ cement by RHA leads to the most promising performance in terms of high ductility, resistance to crack propagation, decrease in the water absorption and voids content and heat at hydration.
\end{abstract}

Keywords: Engineered Cementitious Composites, Rice Husk Ash, Mechanical behavior, Durability.

\section{INTRODUCTION}

Engineered Cementitious Composites (ECC) were designed based on the micromechanics principles. They comprise a special type of High Performance Fiber Reinforced Cementitious Composite (HPFRCC) containing up to $2 \%$ by volume of microfibers with bonding characteristics that enable the material to reach high tensile ductility [1].

ECC has high capacity to absorb energy and to deform under tensile loading, resulting in multiple cracks with small opening during the rupture process of this composite. To achieve this high ductility only a small amount of fine aggregate is added to the mix to control tenacity and no coarse aggregate is used. It is also important to control the matrix strength, since lower matrix strength leads to higher stresses to the fibres, thus causing the multiple cracking effect [2].

Quian and $\mathrm{Li}$ [3] say that this type of composite is able to reach high deflections in bending tests. This high strain bending capacity has led ECC to be recognised, in a popular way, as bendable Concretes [4].

To achieve this high deflection, relationships between macroscopic mechanical behaviour were established and the individual properties of each phase of the composite (fibre, matrix and fibre-matrix interface) were studied. $\mathrm{Li}$ [1] says that the parameters and concepts of micromechanics contributed to an optimization of the fibre composites with the development of cementitious matrixes with rational fibre dosages and high performance.

ECC presents high strain capacity after reaching the elastic peak load causing the strain-hardening process. This behaviour leads to the development of multiple small opening cracks instead of a single large opening crack. This process occurs due to loading transfer among cracks, at which a loaded fibre transfers the load to another point thus creating a new cracking. This repetitive process results in multiple cracking and increases the ductility of the composite, allowing the material to have a more ductile behaviour with strains 
above $3 \%$ [1].

ECC was originally designed by Li [2] with the use PVA (Polyvinyl Alcohol) fibres. Since the use of PVA fibres is not viable in Brazil due to the high importation costs and the reduced amount for commercial applications, Garcez [4] studied the viability to use polypropylene fibres instead of PVA fibres. Polypropylene fibres have very similar characteristics than PVA fibres with the advantage of being commercialised in Brazil with a more reasonable cost.

The results presented by Garcez [4] show that it is viable to use the polypropylene fibres instead of PVA fibres, since both fibres showed similar mechanical results when used in ECC mixtures.

The production of ECC requires two or three times higher amount of cement than in conventional concrete. Aiming to reduce the amount of cement due to environmental and cost issues, Wang and $\mathrm{Li}$ [2] and Yang et al. [5] studied the use of pulverised fly ash as a secondary binder to partial replace Portland cement. According to the authors, the use of fly ash contributes to the development of strain-hardening since the pozolan addition controls the tenacity of the matrix thus avoiding an exaggerated clipping of the fibres. This occurs because the pozolanic reaction develops slower than the cement particle hydration, which means that the use of fly ash leads to a softer evolution of strength and tenacity at early ages and contributes to an increase in strength due to ageing.

In the last five years, the Laboratory of Tests and Structural Models (Laboratório de Ensaios e Modelos Estruturais - LEME/UFRGS) in Brazil has developed studies in this field aiming to include local materials in ECC. In this context, polypropylene fibres have been used linked to the use of fly ashes and rice husk ash (RHA) to develop more economically viable and greener mixtures. Two fundamental questions related to the durability of the composite must be addressed: first, the mixture generates a high amount of heat during hydration, which could lead to premature microcracking; second, the material has the capacity to redistribute stresses leading to multiple cracking even at high strains.

This study aims to evaluate the initial results on the use of processed and non-processed rice husk ash as secondary binder to partial replace Portland cement in ECC mixtures, analysing their behaviour in terms of direct tensile and four-point bending tests.

\section{EXPERIMENTAL PROGRAMME}

This section presents the materials and mix proportions used, followed by the methodology established for the research.

\subsection{Materials}

The main components of the ECC matrix are the Portland cement, fine sand, rice husk ash, water and superplasticiser. The Portland cement used was CP V-ARI (according to Brazilian Standard ABNT NBR 5733 [10], where ARI stands for High Initial Strength), with specific weight of $3.11 \mathrm{~g} / \mathrm{cm}^{3}$, average diameter of $9.65 \mathrm{~mm}$ and loss on ignition of $3.06 \%$. The quartz natural sand has specific weight of $2.52 \mathrm{~g} / \mathrm{cm}^{3}$, fineness modulus of 0.67 and maximum diameter of $0.3 \mathrm{~mm}$.

The superplasticiser used in this study was a polycarboxylic ether based. This type of admixture has high efficiency in reducing the water content compared to the most commonly used admixtures.

Polypropylene fibres are used as reinforcement to the cementitious matrix of ECC. Polypropylene is characterised by an odourless, colourless and nontoxic plastic with a specific weight of approximately 900 $\mathrm{kg} / \mathrm{m}^{3}$. This study analysed the amount of $2 \%$ by volume of fibres. The properties of the polypropylene fibres used in this work are shown in Table 1.

Table 1: Properties of polypropylene fibres.

\begin{tabular}{l|c}
\hline \multicolumn{2}{l}{ Properties of polypropylene fibres } \\
\hline Specific weight $\left(\mathrm{g} / \mathrm{cm}^{3}\right)$ & 0.91 \\
\hline Length $(\mathrm{mm})$ & 10.00 \\
\hline Diameter $(\mu \mathrm{m})$ & 12.00 \\
\hline Tensile Strength $(\mathrm{MPa})$ & 850.00 \\
\hline Elongation at failure $(\%)$ & 21.00 \\
\hline Elasticity Modulus $(\mathrm{GPa})$ & 6.00 \\
\hline Alkalis resistance & Excellent \\
\hline
\end{tabular}


The non-processed rice husk ash is generally used as heating source for the parboiling process of rice grains. The rice husk instantly burned in furnaces results in an ash which is predominantly black or dark gray. The ash gradation was reduced in a ball mill with $310 \mathrm{~mm}$ in length and $275 \mathrm{~mm}$ in diameter containing 75 balls with $38 \mathrm{~mm}$ in diameter each. The ash was grinded for 4 and 8 hours. The chemical composition and the physical properties of the RHAs used in this study are presented in Table 2.

Table 2: Chemical and physical properties of rice husk ash.

\begin{tabular}{l|c|c}
\hline Chemical composition (\%) & Rice Husk Ash (4 hours) & Rice Husk Ash (8 hours) \\
\hline $\mathrm{SiO}_{2}$ & 63.26 & 65.83 \\
\hline $\mathrm{K}_{2} \mathrm{O}$ & 1.46 & 1.07 \\
\hline $\mathrm{CaO}$ & 0.73 & 0.44 \\
\hline $\mathrm{P}_{2} \mathrm{O}_{5}$ & 0.52 & 0.33 \\
\hline $\mathrm{Fe}_{2} \mathrm{O}_{3}$ & 0.32 & 0.34 \\
\hline $\mathrm{MnO}$ & 0.30 & 0.27 \\
\hline $\mathrm{SO}_{3}$ & 0.18 & 0.05 \\
\hline $\mathrm{Al}_{2} \mathrm{O}_{3}$ & 0.13 & 0.06 \\
\hline $\mathrm{MgO}_{\mathrm{CO}}$ & 0.12 & 0.08 \\
\hline $\mathrm{CO}_{2}$ & 32.71 & 31.33 \\
\hline $\mathrm{Physical} \mathrm{properties}_{\text {Specific mass }\left(\mathrm{g} / \mathrm{cm}^{3}\right)}$ & 2.06 \\
\hline Average grain size $(\mu \mathrm{m})$ & 2.03 & 3.59 \\
\hline Loss on ignition $(\%)$ & 7.29 & 13.99 \\
\hline Pozzolanic activity index $(\%)$ & 19.44 & 162.48 \\
\hline
\end{tabular}

\subsection{Casting of specimens}

The materials were mixed in a mechanical planetary mixer normally used for mortars, with a maximum capacity of 2 litres. The dry materials (cement, sand and RHA) were mixed until the powder mixture is considered uniform. Water and the superplasticiser were then added to the mix.

The paste obtained in this stage is extremely fluid to allow good fibre dispersion, which is obtained by mixing the materials, including the fibres, at high speed for 3 minutes.

\subsection{Research Method}

In this experimental programme 7 ECC mixtures were analysed. Table 3 presents the mix proportions studied. Codes for mixes with RHA grinded for 4 hours and 8 hours start by 4RHA and 8RHA, respectively. For both ashes grinded for 4 and 8 hours, three percentages of cement replacement (by volume) were studied: 10\%, $20 \%$ and $30 \%$. Codes for these mixes finalise with 10, 20 and 30, respectively. A reference mix was used with no RHA replacement for comparison purposes.

All mechanical tests were carried out at 28 days after casting. Four specimens were cast for each mix proportion and each type of test carried out (tensile and flexural).

Table 3: Chemical and physical properties of rice husk ash.

\begin{tabular}{l|c|c|c|c|c|c|c}
\hline Code & Description & Cement & RHA & Quartz Sand & Fibre & Superplasticiser & Water \\
\hline ECC-reference & Reference & 1009.16 & --- & 757.53 & 17.90 & 7.05 & 348.55 \\
\hline 4RHA10 & 10\% RHA 4 hours & 908.24 & 65.87 & 757.53 & 17.90 & 7.05 & 348.55 \\
\hline 4RHA20 & 20\% RHA 4 hours & 807.32 & 131.74 & 757.53 & 17.90 & 7.05 & 348.55 \\
\hline 4RHA30 & 30\% RHA 4 hours & 706.41 & 197.61 & 757.53 & 17.90 & 7.05 & 348.55 \\
\hline 8RHA10 & 10\% RHA 8 hours & 908.24 & 68.14 & 757.53 & 17.90 & 7.05 & 348.55 \\
\hline 8RHA20 & 20\% RHA 8 hours & 807.32 & 136.28 & 757.53 & 17.90 & 7.05 & 348.55 \\
\hline 8RHA30 & 30\% RHA 8 hours & 706.41 & 204.43 & 757.53 & 17.90 & 7.05 & 348.55 \\
\hline
\end{tabular}

To evaluate the behaviour of the specimens in terms of direct tensile test, this study followed the test setup proposed by Boshoff e Zijl [6], with loading speed of $5 \mathrm{~N} / \mathrm{s}$. The geometry of the specimens is shown in Figure 1. 


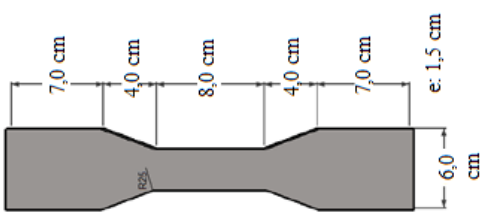

(a)

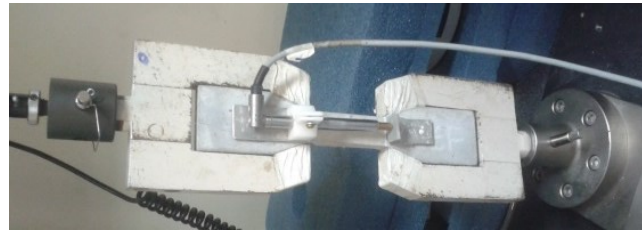

(b)

Figure 1: Specimen used for direct tensile test: (a) Specimen with its dimensions, (b) Tested specimen.

The bending test followed the work developed by Magalhães [7], which was originally based on ASTM C1609 [8]. The geometry of the specimens is $300 \mathrm{~mm}$ in length, $70 \mathrm{~mm}$ in width and $15 \mathrm{~mm}$ in thickness. The load is applied following the four-point bending scheme and is equally divided into two concentrated forces applied $77 \mathrm{~mm}$ from the supports with total span of $231 \mathrm{~mm}$. Figure 2 shows a specimen during testing, with one LVDT measuring the vertical displacement and another measuring the horizontal displacement.

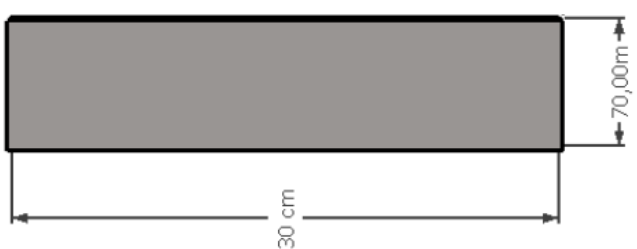

(a)

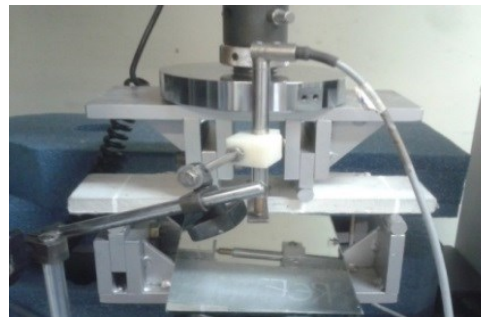

(b)

Figure 2: Bending test: (a) Specimen with its dimensions, (b) Tested specimen.

\subsection{Water Absorption and Void Content}

To obtain a durability indication, it was analyzed the water absorption and void content of the composites. The test was conducted in accordance with Brazilian standard NBR 9778 [11]. Table 4 shows the experimental strategy for the test.

Table 4: Experimental details - water absorption and void content.

\begin{tabular}{l|l}
\hline Specimen size & $\mathrm{d}=5 \mathrm{~mm} / \mathrm{h}=100 \mathrm{~mm}$ \\
\hline Age & 28 days \\
\hline Number of samples & 4 by type of composite \\
\hline Replacement of cement by RHA & $30 \%$ \\
\hline Grind time of RHA & 4 hours / 8 hours \\
\hline
\end{tabular}

\subsection{Hydration heat}

The test consists in measuring the temperature during the initial of cement hydration process. A standard curve of hydration heat is usually composed of a sudden increase in temperature (i.e., peak of reactions) until the moment which the temperature stabilizes. So the hydration reactions reduce considerably. This test method was developed for this study purpose and aims only to compare the composites analyzed, as described in following.

After mixing, the composite were placed inside a mold $(30 \times 12 \times 5 \mathrm{~cm})$ and connected to a thermocouple type K. Thereafter, the specimens was placed in a styrofoam box and sealed with adhesive tape to avoiding the interference of the external environment and create adiabatic process, as shown in Figure 3 . The heat by time was registered by FieldLogger software through the connection of the thermocouple. The hydration heat was evaluated until 7 days of test. It is important to note that the method used does not follow a standard procedure and it is designed exclusively for this research. In this experimental test it was analyzed 
only composites with $30 \%$ of rice husk ash (RHA) milled for 4 hours and 8 hours.

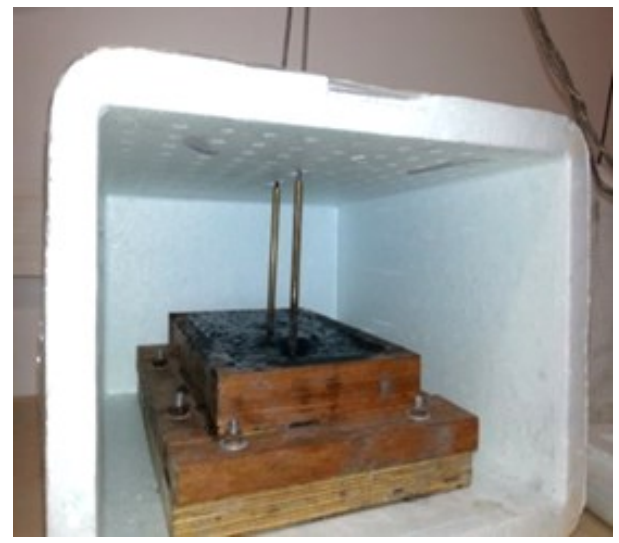

Figure 3: Sample conditioning in the adiabatic process.

\section{RESULTS AND DISCUSSION}

\subsection{Tensile Test}

The results of the uniaxial tensile tests for mixtures with RHA grinded for 4 hours are presented in Figure 4 (a) and Table 4. It can be observed a considerable increase in the strain capacity of the composite mixtures after cracking. Mixtures in this figure had their first crack occurring at stresses varying from 0.92 to 1.64 MPa.

It can be observed a loss in performance for the RHA mixtures in comparison with the reference mixture. The RHA mixtures present strain-hardening process with maximum stresses varying from 2.06 to 2.26 $\mathrm{MPa}$, while the maximum stress for the reference mixture was $3.09 \mathrm{MPa}$.

Mixture 4RHA10 presents multiple cracking behaviour with maximum stress around $2.18 \mathrm{MPa}$ and strain of $1.3 \%$. Mixture 4RHA20 presents poorer behaviour in comparison to the other mixtures with RHA, having the first crack appearing at the stress of $0.92 \mathrm{MPa}$.

Mixture 4RHA30 presents the best performance among the RHA mixtures with maximum stress of $2.26 \mathrm{MPa}$ and strain of $1.3 \%$. It can be noted that the multiple cracking effect is not as clear as in the reference mix, however, the strain capacity is higher than the reference.

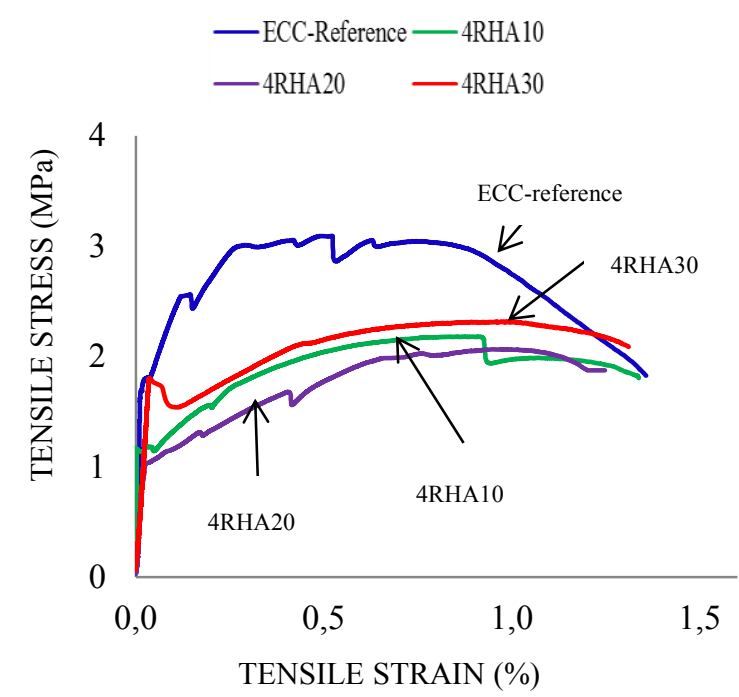

(a)

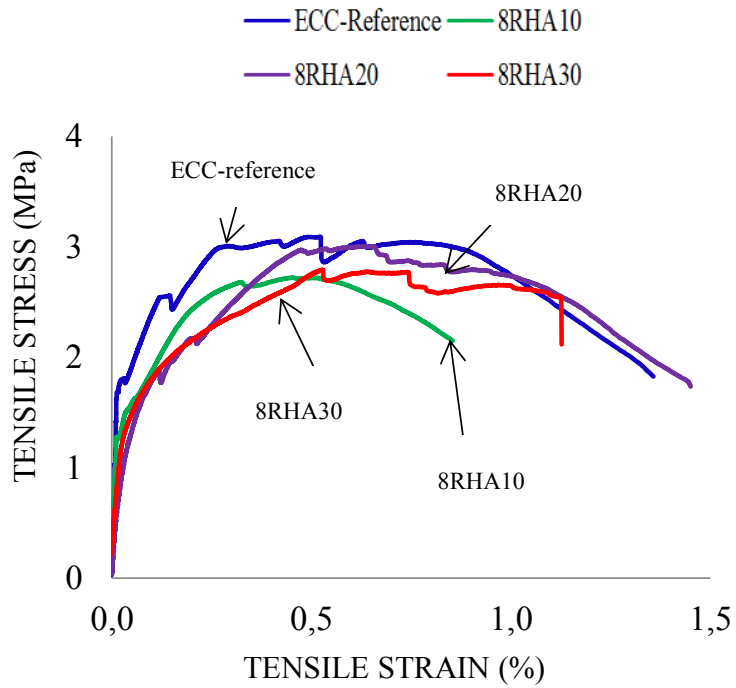

(b)

Figure 4: Stress-strain curve for direct-tensile test - RHA 4 hours (a) and RHA 8 hours (b). 
Mixtures with RHA grinded for 8 hours (Figure 4 (b)) present an increase in the strain capacity leading to strain-hardening. This process occurs due to the stress transfer bridges among the fibres. Table 5 shows that the strain for 8RHA mixtures ranges from 1.1 to $1.4 \%$, which is similar to the reference mix.

Mixture 8RHA10 shows a considerable loss in performance in comparison to the other RHA percentages. Moreover, the multiple cracking effect is not clear and the cracks start to appear when stress is around 1.14 MPa. The maximum stress for this mixture is $2.67 \mathrm{MPa}$.

Mixture 8RHA20 presents similar behaviour as the reference mixture, showing a clear multiple cracking effect and the first crack appearance when the stress and strain are around $1.85 \mathrm{MPa}$ and $1.4 \%$, respectively.

The first crack for mixture 8RHA30 occurs at higher strain and stress than the other mixtures, including the reference. The multiple cracking effect is very clear in this mixture.

Table 5: Tensile properties of mixtures.

\begin{tabular}{l|c|c|c|c}
\hline \multicolumn{1}{c|}{ Code } & Description & $\begin{array}{c}\text { First cracking strength } \\
(\mathbf{M P a})\end{array}$ & $\begin{array}{c}\text { Maximum flexural strength } \\
\mathbf{( M P a})\end{array}$ & Tensile strain (\%) \\
\hline ECC-reference & Reference & $1.8 \pm 0.2$ & $3.09 \pm 0.1$ & $1.2 \pm 0.3$ \\
\hline 4RHA10 & 10\% RHA 4 hours & $1.09 \pm 0.4$ & $2.18 \pm 0.2$ & $1.3 \pm 0.2$ \\
\hline 4RHA20 & 20\% RHA 4 hours & $0.92 \pm 0.2$ & $2.06 \pm 0.5$ & $1.1 \pm 0.1$ \\
\hline 4RHA30 & 30\% RHA 4 hours & $1.64 \pm 0.3$ & $2.26 \pm 0.3$ & $1.3 \pm 0.2$ \\
\hline 8RHA10 & 10\% RHA 8 hours & $1.14 \pm 0.1$ & $2.67 \pm 0.4$ & $1.4 \pm 0.2$ \\
\hline 8RHA20 & 20\% RHA 8 hours & $1.85 \pm 0.6$ & $3.01 \pm 0.3$ & $1.4 \pm 0.5$ \\
\hline 8RHA30 & 30\% RHA 8 hours & $2.78 \pm 0.2$ & $2.76 \pm 0.1$ & $1.1 \pm 0.4$ \\
\hline
\end{tabular}

\subsection{Flexural Test}

Figure 5 presents the results of the four-point bending test and Table 5 shows the quantitative results for both RHAs studied. For the mixes with RHA, the maximum stress was around $8 \mathrm{MPa}$, similar to the reference mix. As the cement replacement percentage increases, the ultimate strain also increases. This can be attributed to the ash addition, which improves fibre dispersion. According to Kim et al. [9], fibre dispersion is improved by the workability of the mixture. This tendency, however, must be verified through fibre dispersion tests, which were not carried out in the present work.

Mixture 4RHA10 (Figure 5 (a)) presents the maximum stress higher than ECC-reference, around 9.59 $\mathrm{MPa}$. On the other hand, this mixture presented lower strain than the other mixtures, with maximum of $2.4 \%$. The multiple cracking effect is not clear.

Mixture 4RHA20 shows very similar behaviour to mixture 4RHA10, with maximum stress of 6.8 $\mathrm{MPa}$ and cracking starting at 4.20 MPa, as shown in Table 6. Mixture 4RHA30 presents a clear strainhardening effect, which means that the bridge process of the fibres allowed the multiple cracking to occur. This mixture presents maximum stress of $8.58 \mathrm{MPa}$, which is higher than the reference mix, and a $5.8 \%$ strain. This mixture seems to be a viable alternative due to the gain in environmental sustainability. The amount of $30 \%$ contributes to a reduction on the use of Portland cement and the 4 hours grinding time is more viable than 8 hours due to the lower energy consumption.

Table 6: Flexural properties of mixtures.

\begin{tabular}{l|c|c|c|c}
\hline \multicolumn{1}{c|}{ Code } & Description & $\begin{array}{c}\text { First cracking strength } \\
\text { (MPa) }\end{array}$ & $\begin{array}{c}\text { Maximum flexural strength } \\
\text { (MPa) }\end{array}$ & Tensile strain (\%) \\
\hline ECC-reference & Reference & $4.79 \pm 0.3$ & $8.02 \pm 0.1$ & $5.8 \pm 0.5$ \\
\hline 4RHA10 & 10\% RHA 4 hours & $6.10 \pm 0.4$ & $9.54 \pm 0.2$ & $2.4 \pm 0.1$ \\
\hline 4RHA20 & 20\% RHA 4 hours & $4.20 \pm 0.2$ & $6.8 \pm 0.5$ & $2.8 \pm 0.6$ \\
\hline 4RHA30 & 30\% RHA 4 hours & $6.49 \pm 0.6$ & $8.58 \pm 0.2$ & $5.8 \pm 0.2$ \\
\hline 8RHA10 & 10\% RHA 8 hours & $4.52 \pm 0.2$ & $7.60 \pm 0.3$ & $3.9 \pm 0.4$ \\
\hline 8RHA20 & 20\% RHA 8 hours & $5.0 \pm 0.5$ & $8.17 \pm 0.2$ & $3.6 \pm 0.1$ \\
\hline 8RHA30 & 30\% RHA 8 hours & $4.26 \pm 0.3$ & $8.49 \pm 0.2$ & $7.2 \pm 0.3$ \\
\hline
\end{tabular}




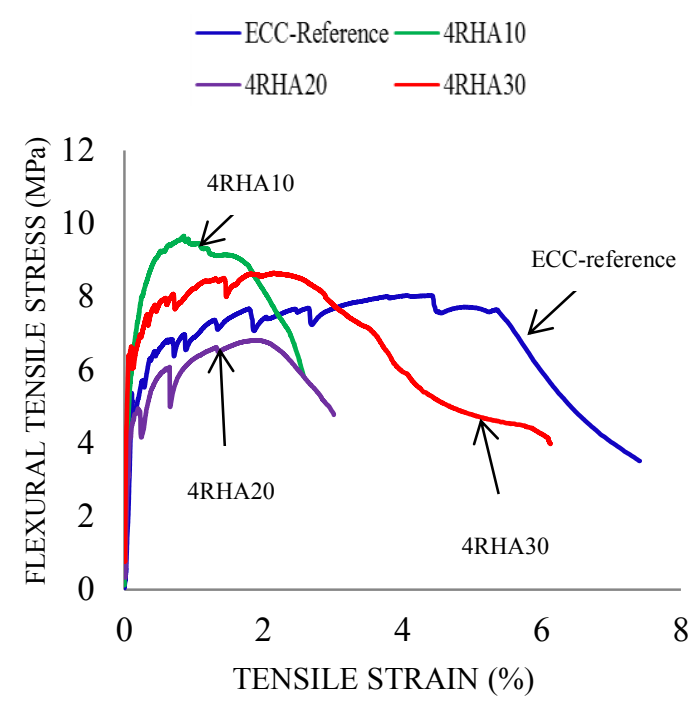

(a)

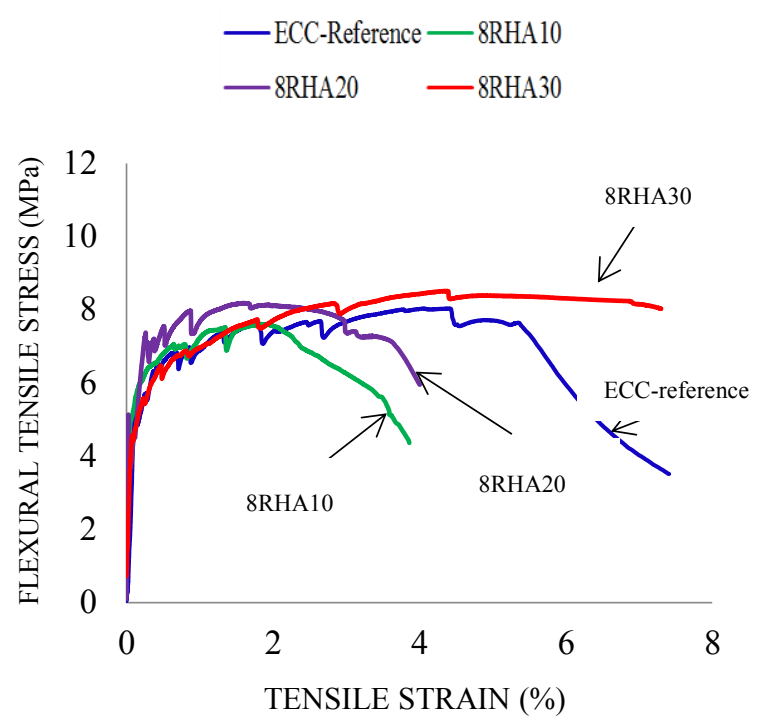

(b)

Figure 5: Stress-strain curve for flexural - RHA 4 hours (a) and RHA 8 hours (b).

For mixtures with RHA grinded for 8 hours, it is possible to note that the multiple cracking effect is more evident as the cement replacement percentage increases.

Mixture 8RHA10 cracked at the stress of 4.52 MPa. The strain-hardening effect is then developed following a multiple cracking process, with maximum strain of 3.9\%. Mixture 8RHA20 has similar behaviour as mixture 8RHA10 with cracking around $5 \mathrm{MPa}$ and ultimate strain around $3.6 \%$. This mixture presents maximum stress higher than the reference ECC.

Mixture 8RHA30 presents clear multiple cracking behaviour, as shown in Figure 5 (b). It can be noted that the maximum stress observed, around $8.49 \mathrm{MPa}$, is similar to the reference mix (Table 5). The mixture also shows a gain in ultimate strain, around $7.2 \%$, which is higher than the reference mix. This mix proportion presents the best mechanical behaviour compared to the RHA composites and the overall behaviour is similar to the reference mix.

\subsection{Water Absorption and Void Content}

The Figure 6 (a) and (b) shows the average results of three measurements for water absorption and void content respectively. Analyzing Figure 6 (a) it can be observed that the rice husk ash composite grinded for 8 hours showed an absorption similar to the reference composite. However, the rice husk ash composite grinded for 4 hours showed an increase in the absorption. It is believed that this behavior has occurred due to its higher average particle size than rice husk ash grinded for 8 hours, which probably decrease the marshaling of materials mixing. This fact can be verified by the average particle size of both composites. The rice husk ash grinded for 4 hours has an average size of $7.29 \mu \mathrm{m}$ while the rice husk ash grinded for 8 hours achieve an average size of $3.59 \mu \mathrm{m}$ (i.e., $49 \%$ higher), which induces in a more porous cementitious matrix.

In relation to Figure 6 (b) it can be observed that the same behavior was obtained. The rice husk ash composite grinded for 4 hours showed a void content higher than others composites. Nevertheless, for the rice husk ash grinded for 8 hours it is observed a tendency of lower void content when compared to reference composite. This fact also can be justified probably due to the pore refinement by the mixture with rice husk ash, which has a smaller particle size, resulting in a more compact cementitious matrix. 


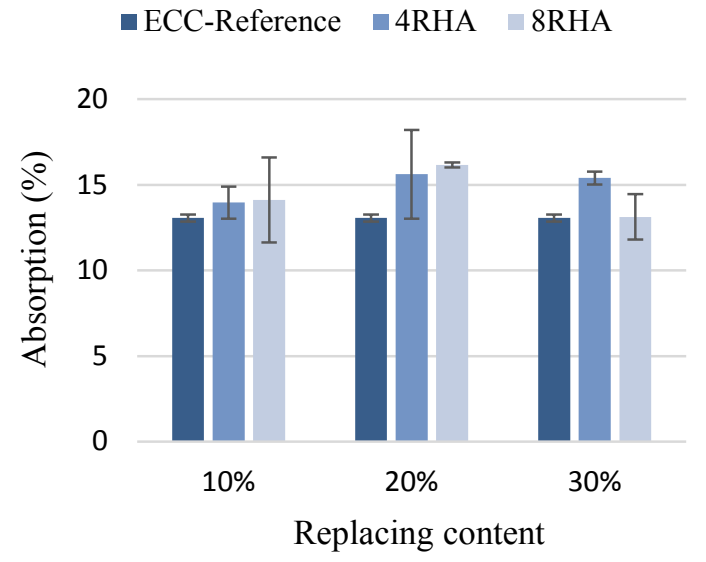

(a)

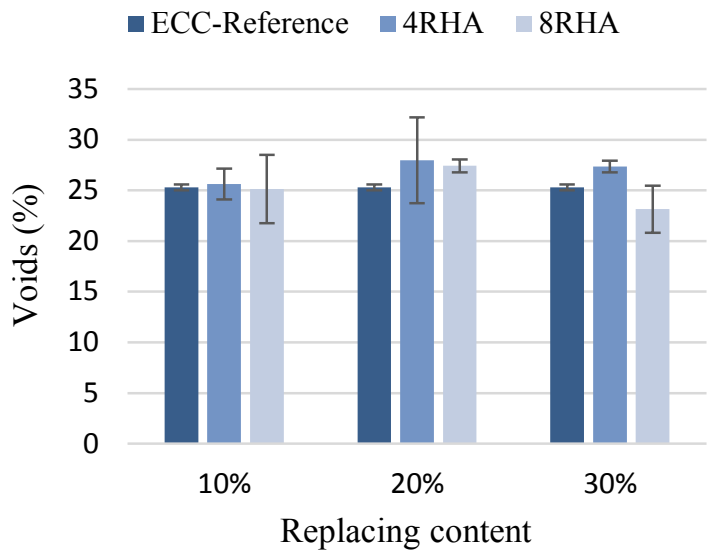

(b)

Figure 6: (a) water absorption (b) void content.

\subsection{Hydration heat}

The curve of hydration obtained demonstrates a very similar behavior found by Alves [12]. This means that when pozzolans are used, the hydration kinetics is slower. Figure 7 illustrates the curve of hydration heat for composites with $30 \%$ of cement replaced by rice husk ash. It can be observed that the two mixtures with rice husk ash (4 hours and 8 hours) showed softer hydration curves and a maximum heat peak less pronounced than the reference composite. It can also be noticed that with the increase in days of testing, the heat becomes softer in all composites. So it is possible to appoint that the decrease in heat by the rice husk ash composites can be explained by the fact that pozzolanic reaction of the rice husk ash is more slowly.

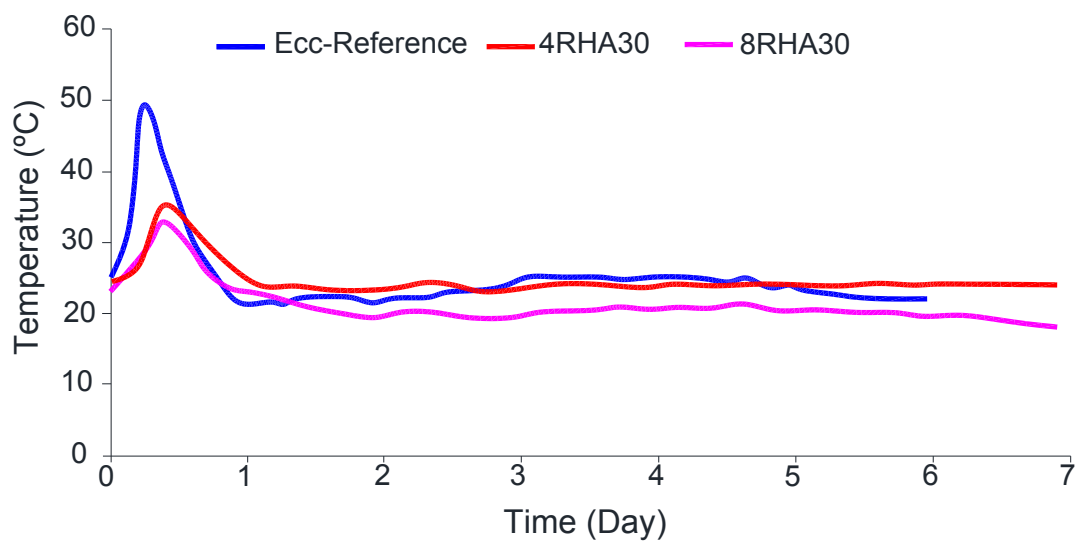

Figure 7: Curves of hydration heat.

\section{CONCLUSIONS}

The following concluding remarks can be driven based on the results of this study:

The use of rice husk ash in ECC contributes to the production of a greener material since it partially replaces the Portland cement of the mixtures (thus reducing the amount of $\mathrm{CO} 2$ released by cement production) and also reutilises a residue material (which would probably be discarded in landfills);

Results obtained from direct tensile tests show that the percentage of $30 \%$, regardless the grinding time, is the one with the best performance;

Results obtained from flexural tests show that the RHA addition contributes to an improvement in tenacity of the matrix, which led to multiple cracking for all amounts of RHA studied. Specimens with $30 \%$ RHA shows the best results in terms of ultimate strain.

The mechanical tests carried out shows that 8RHA30 mixture presents the best results, in many aspects, 
which are even greater than the reference mix. Mixture 4RHA30 also presents good results. Aiming for a more environmentally friendly alternative, this mixture seems to be more viable due to lower grinding time and energy cost.

Concerning the durability issues, about the water absorption test and voids content, it can be concluded that the 30\% cement by RHA grinded for 8 hours showed more satisfactory results than the composite grinded for 4 hours. For the hydration heat, it was observed that rice husk ash reduces the heat in early hours, leading to curves without large temperature peaks, which benefits the prevention of autogenous cracks in the composite.

Generally, the ECC developed in Brazil with the use of rice husk ash and polypropylene fibres seems viable. This is because the composite presents a clear strain-hardening effect, which is one of the main characteristics for ECC.

\section{ACKNOWLEDGEMENTS}

The authors would like to acknowledge the financial support of CNPQ (National Counsel of Technological and Scientific Development) and the physical infrastructure of the Laboratory of Tests and Structural Models (LEME) of the Federal University of Rio Grande do Sul (UFRGS) where the study was carried out.

\section{BIBLIOGRAPHY}

[1] LI, V.C. "Engineered cementitious composites (ECC): a review of the material and its aplications", Journal of Advanced Concrete Technology, v.1, n.3, pp.215-230, 2003.

[2] WANG, S., LI, V.C. "Engineered cementitious composites with high-volume fly ash", ACI Materials Journal, v.104, n.3, pp.233-240, 2007.

[3] QUIAN, S., LI, V.C. "Simplified inverse method for determining the tensile strain capacity of strain hardening cementitious composites", Journal of Advanced Concrete Technology, v.5, n.2, pp.235-246, 2007.

[4] GARCEZ, E.O. Investigação do comportamento de engineered cementitious composites reforçados com fibras de polipropileno como material para recapeamento, Tese de D.Sc, Programa de Pós-Graduação em Engenharia Civil, Universidade Federal do Rio Grande do Sul, 2009.

[5] YANG, E.H., YANG, Y., LI, V.C. "Use of high volumes of fly ash improve ECC mechanical properties and material greenness", ACI Materials Journal, v.104, n.6, pp.620-628, 2007.

[6] BOSHOFF, W.P., ZIZL, G.P.A.G. "Time-dependent response of ECC: characterization and modeling of creep and creep fracture", International RILEM Workshop on HPFRCC in Structural Applications, Honolulu, PRO 49, pp.125-134, 2005.

[7] MAGALHÃES, M.S. Caracterização experimental de compósitos cimentícios reforçados com fibras de PVA: processo de fratura, propriedades térmicas, deformações diferidas e estabilidade térmica, Tese de D.Sc.,, Programa Coimbra de Pós-Graduação e Pesquisa de Engenharia Civil, Universidade Federal do Rio de Janeiro, 2010.

[8] ASTM C 1609: Standard Test Method for Flexural Performance of Fiber-Reinforced Concrete, (Using Beam with Third-Point Loading).

[9] KIM, J.K., KIM, J.S., HA, G., KIM, Y. "Tensile and fiber dispersion performace of ECC ( engineered cementitious composites) produced with group granulated blast furnace slag", Cement and Concrete Research, v.37, pp.1096-1105, 2007.

[10] Associação Brasileira de Normas Técnicas, Cimento Portland de alta Resistência Inicial, NBR: 5733, Rio de Janeiro, 1991.

[11] Associação Brasileira de Normas Técnicas, Argamassas e Concreto Endurecidos - Determinação da Absorção de Água por Imersão - Índice de Vazios e Massa Específica, NBR 9778, Rio de Janeiro, 2005.

[12] ALVES, N.J.D. Avaliação dos Aditivos Incorporadores de Ar em Argamassas de Revestimento, Dissertação de M.Sc., Universidade de Brasília, Brasília, DF, 2002. 